\title{
Application of Value Management in Conception of Construction Projects in Rwanda
}

\author{
Rwamuhinda Dick, Abednego O. Gwaya, Githae Wanyona
}

\begin{abstract}
Value Management (VM) and Value Engineering (VE) are techniques concerned with defining, maximizing and achieving "value for money". It should be noted that VM is not about reducing the cost but about adding value and where necessary the cost can be added to achieve value. Despite its proven significance in securing maximum output from limited resources, this approach is not a common practice in Rwanda's construction Industry. This study therefore defines VM and describes all the processes and techniques involved in it. The merits and demerits of VM process in construction projects are discussed in details and relevance of its uses is discussed and recommended in consideration of the scope and complexity of the projects as well as the risks involved. While the benefits of a value management review are often perceived in terms of improved quality and reduced cost, this report discusses the exercise as a functional mechanism to measure value, taking into account monetary and non-monetary benefits and thus demonstrating value for money. While the author has not been able to obtain relevant literature on VM practice in Rwanda, It can be deduced from the review of the related literature that most of the evaluation techniques conducted for construction projects in developing world have mostly relied on evaluation of project performance in terms of cost, quality, delivery and progress. Since project evaluation is carried out after the work has been undertaken, the output of the analysis will just give the client an indication or a good understanding of the project performance. Such evaluations only reveal the competence or incompetence of the project participants instead of providing value for money which is addressed by VM practice which is an ex-ante analysis that takes into consideration of all value parameters. The study used a quantitative survey method of research to obtain responses from professional practitioners in construction industry in Rwanda. The sample size of 115 were selected from members of professional practitioners in the construction industry out of which 106 members were responsive. Finally, it is concluded that VM approach is not used in construction industry in Rwanda and recommended that VM practice be adopted in construction industry in Rwanda as a mandatory requirement for conception of all construction projects with a budget of \$20M and above.
\end{abstract}

Index Terms: Conception of construction projects, Construction projects, value engineering, value management.

Revised Manuscript Received on October 10, 2019.

* Correspondence Author

Dick Rwamuhinda, Department of Construction Management, Jomo Kenyatta University of Agriculture and Technology, Nairobi, Kenya. Email: rwamuhinda@gmail.com

Dr. Abednego O. Gwaya, Department of Construction Management, Jomo Kenyatta University of Agriculture and Technology, Nairobi, Kenya. Email: agwaya@jkuat.ac.ke

Dr. Githae Wanyona, Department of Construction Management, Jomo Kenyatta University of Agriculture and Technology, Nairobi, Kenya. Email: gwanyona@jkuat.ac.ke

(c) The Authors. Published by Blue Eyes Intelligence Engineering and Sciences Publication (BEIESP). This is an open access article under the CC BY-NC-ND license (http://creativecommons.org/licenses/by-nc-nd/4.0/)

\section{INTRODUCTION}

Construction industry has grown so rapidly in Rwanda after the war and genocide against Tutsi in 1994. Construction industry has grown so rapidly in Rwanda after the war and genocide against Tutsi in 1994. Statistics obtained from Rwanda National Institute of Statistics indicate that the Industry sector was expected to grow at $8.3 \%$ in 2018 and $13.1 \%$ in 2019 boosted by mining and construction resulting from the ongoing international mineral prices and the construction of a new Airport and other project from private sector. Construction alone was expected to contribute to the GDP growth by 5.2\% in 2018 and increase with double digit ie $10.1 \%$ in the year 2019 . Construction and manufacturing are also among areas where most jobs have been created in the last two years, along with other sectors such as accommodation and food production as well as storage. [3]. Looking at the number of new jobs created between 2017 and 2018, the survey indicated that some economic activities have seen an increase in employed people while others have seen a decrease.

Among the economic activities that show an increase in the number of employed people, construction has the highest increase with 52,171 workers, followed by manufacturing with 42,409 workers, accommodation and food service activities with 25,871 people

\section{BACKGROUND}

The growth of construction industry in Rwanda has taken place amid monumental challenges ranging from lack of local skills to expensive and scarce construction materials available locally due to the country's isolation from the sea. In effect, big and complex infrastructure projects that have so far been put in place have not been done in consideration of the value analysis at any stage of construction. Thus, notable frivolous scope changes, redundant facilities, huge and unjustifiable costs. As stated above construction projects in Rwanda, be public or private, are being implemented in abundance and at a very large scale. [4] There is so far in record, some public infrastructure projects notably those of energy generation which have been completed but functioning at the minimum and lower levels of their initial intended production. [5]. In this case the essence of VM or lack of it has to be assessed and come up with possible culprit and measures to be taken to avert the recurrence of the same in future similar projects in nature and volume. There are other construction projects that have also been implemented in Rwanda without careful consideration of their effects to the surrounding environment such that their completion and commissioning for use has led to elimination and/or relocation of some existing infrastructure, or led to creation of other elements that were not to be part of the project output had the designs taken care of some environmental factors in the initial stage of their conception. [6].

\section{Published By:}

Blue Eyes Intelligence Engineering \& Sciences Publication

(C) Copyright: All rights reserved. 
This research will benefit individuals and institutions in construction industry in Rwanda to plan and implement infrastructure projects in a manner that enhances value for money. In effect recommend the use of value management concept in construction industry in Rwanda and proposes its mandatory requirement during conception of large and complex public infrastructure projects.

\section{LITERATURE REVIEW}

\section{A. Concept of Value Management}

Value management is a systematic and structured process of team-based decision making. It aims to achieve the best value for a project by defining those functions required to achieve the value objectives and delivering those functions at the least cost (whole life cost or resource use), consistent with the required quality performance. VM can also be described as a systematic, multi-disciplinary effort directed towards analyzing the functions of projects for the purpose of achieving the best value at the lowest overall life cycle costs. The Value management definition in last decades can be identified with five keywords or phrases, according to Rangelova \& Traykova, 2014 [1]. Systematic, multi-disciplinary, function, value and life cycle costs.

\section{B. Value Management in Perspective}

The industry and its customers are broadening their interpretation of value, and beginning to appreciate the subjective nature of it by adding concerns surrounding environment and society (Thomson, Austin, Mills, \& Devine-Wright, 2003). This assertion was corroborated by Karim, Rahmin, Danuri, and Mohamed (2014) \& Fong and Shen (2000) which noted that value management (VM) practices have been expanded and became a well-received technique globally and that organizations are now progressing towards a better implementation of VM and should be assessing their strengths and weaknesses in order to move forward competitively. At present, VM is widely accepted and practiced in many countries (Karim et al., 2014). For example, the US government has mandated that all projects that cost USD2 million or more must adopt VM study whereas its Department for Transport (DfT) has been more stringent, making it compulsory for projects as low as USD100 thousands (Kaur, 2012). Meanwhile, Kim, Lim, Kim and Cheon (2010) asserted that the South Korean Ministry of Land, Transport and Maritime affairs has made it mandatory to apply VM for construction projects of KRW10 billion (USD10 million) or more. The Japanese government has also mandated the use of VM for projects costs JPY175 million (USD2 million) or more and the Australian government implemented VM for its federal projects costs of at least AUD5 million (USD4.5 million) (Karim et al., 2014). Kelly et al. 2004 observed that VM in the UK construction industry has evolved to become 'an established service with commonly understood tools, techniques, and styles'. Ellis, Wood and Keel (2005) describe VM as 'widely accepted as an important tool in the management of projects'. While this may be so for construction industries in developed countries, the situation is by no means so clear for developing nations according to Bowen et al., 2010 [1]

\section{Risks of Value Management in Construction}

There are risks in every activity, including the ones that are conceived for the purpose of managing people, activities and/or processes. The principles of management involve different tools, techniques, procedures and methods for the purpose of planning, controlling and regulating people, events, procedure and /or practice. It is expected that there will be some risks in the adopted tools which is part of the risks of the principles of management. With demonstrated benefits of value management, there are some risks that need to be monitored, evaluated, and responded to for the process to be successfully applied in the construction industry. [7]

\section{Cost of Value Management in Construction}

This section explains the various costs associated with a value management exercise. These costs are incurred before, during, and after the exercise. This is one of the challenging areas when convincing clients and other stakeholders to adopt a value management exercise for their project. However, observations from previous projects where value management was carried out and the recommendations adopted, revealed that the cost of a value management exercise is relatively cheap. The cost is low when compared to the added function to the project as a result of the exercise and the eventual savings on the overall project cost. The major costs of conducting a value management exercise are include the cost of facilitator, the cost of participants and venue, adminstrative costs and information gathering cost.

\section{E. Application of Value Management}

VM can be applied at any point in a project, even in construction. However, typically the earlier it is applied the higher the return on the time and effort invested. The three main stages of a project and VM's application are planning, design and construction as described below. These stages are described as follows: [8].

Planning: At the Planning stage of development, there are additional benefits to be derived from a Value Management Workshop. An independent team can:

\section{Review the program}

2. Perform a functional analysis of the facility

3. Obtain the owner/users definition of value

4. Define the key criteria and objectives for the project

5. Verify/validate the proposed program

6. Review master plan utility options (e.g. Central Utility Plant Versus individual systems)

7. Offer alternative solutions (square footage needs per function, adjacency solutions, etc.)

8. Verify if the budget is adequate for the developed program

The benefit of conducting VM at the early stage of planning is that any changes to the program at this stage have very little if any impact on schedule and $\mathrm{A} / \mathrm{E}$ time and redesign costs. The project will be developed with fewer changes, redesigns, and a greater understanding by all parties of what the final function and space allocations will be. In addition, an independent team can bring a fresh outside view of alternate solutions from other similar projects.

Design: This is the stage that most VM participants are used to becoming involved, when the design has at least made it to the schematic stage. Most government agencies require at least one VM session at the design stage on projects over a certain \$ size. \& Sciences Publication (C) Copyright: All rights reserved. 
The primary tool available to the VM team is the Workshop-typically a 40-hour session (or less for smaller or less complex projects). The Workshop is an opportunity to bring the design team and client together to review the proposed design solutions, the cost estimate, and proposed implementation schedule and approach, with a view to implementing the best value for the money. The definition of what is good value on any particular project will change from client to client and project to project.

During the actual Workshop portion of the VM study, the five-step Job Plan is followed, as prescribed by SAVM International and follows FIVE key steps:

1. Information Phase

2. Speculation (Creative) Phase

3. Evaluation (Analysis) Phase

4. Development Phase (Value Management Proposals)

5. Presentation Phase (Report/Oral Presentation)

\section{Information Phase:}

At the beginning of the VM Study, it is important to:

1. Understand the background and decisions that have influenced the development of the design through a formal design presentation by the design $\mathrm{A} / \mathrm{E}$.

2. Analyze the key functional issues governing the project. The functions of any facility or system are the controlling elements in the overall VM approach. This procedure forces the participants to think in terms of function, and the cost and impacts associated with that function.

3. Define Owner's objectives and key criteria governing the project.

4. Determine Owner's definition of Value.

\section{Speculation (Creative) Phase:}

This step in the VM study involves the listing of creative ideas.

1. The VM Team thinks of as many ways as possible to provide the necessary function within the project areas at a lesser initial or Life-Cycle Cost which represent improved value to the client.

2. Judgment of the ideas is prohibited.

3. The VM Team is looking for quantity and association of ideas, which will be screened in the next phase of the study.

4. Many of the ideas brought forth in the creative phase are a result of work done in the function analysis. This list may include ideas that can be further evaluated and used in the design.

Evaluation (Analysis) Phase:

In this phase of the Project, the VM Team, together with the Client and/or Users:

1. Defines the criteria to be used for evaluation.

2. Analyses and judges the ideas resulting from the worthy of additional study are discarded. Those ideas that represent the greatest potential for cost savings and value improvement are developed further. Weighted evaluation is applied in some cases to account for impacts other than costs (such as schedule impacts, aesthetics, etc.). creative session. Ideas found to be impractical or not

\section{Development Phase:}

During the development phase of the VM study, many of the ideas are expanded into workable solutions. The development consists of:

1. Description of the recommended design change.

2. Descriptive evaluation of the advantages and disadvantages of the proposed recommendation.

3. Cost comparison and LCC calculations.

4. Each recommendation is presented with a brief narrative to compare the original design method to the proposed change.

5. Sketches and design calculations, where appropriate, are also included in this part of the study.

\section{Presentation Phase:}

The last phase of the VM Study is the presentation of the recommendations in the form of a written report. A briefing/oral presentation of results is made to the Client and Users, as well as the Design Team representatives. The recommendations, the rationale that went into the development of each proposal, and a summary of key cost impacts are presented at that time so that a decision can be made as to which Value Management proposals will be accepted for implementation and incorporation into the design documents.

In addition to the monetary benefits, a VM Workshop provides a valuable opportunity for key project participants to come together, then step aside and view the project from a different perspective. The VM process therefore produces the following benefits:

1. Opportunity to explore all possible alternatives

2. Forces project participants to address "value" and "function"

3. Helps clarify project objectives

4. Identifies and prioritizes Client's value objectives

5. Implements accepted proposals into design

6. Provides feedback on results of the study

\section{F. Types of construction projects suitable for VM}

According to Norton, 1995; Rangelova \& Traykova, 2014 [1], there are types of projects that will benefit the most from Value Management. These include costly projects, where VM can result in savings of up to $5-15 \%$ of the total costs involved on the project and therefore it is very cost effective to apply VM to higher cost projects. It is also suitable for complex projects where with VM study one has the opportunity to get expert second opinions, especially, if there are members of the team that are independent of the original design team. On complex projects, it is vital to get expert opinions. By using VM, attention can be given to complex issues. The third type is Repetitive projects. In this case the same type of building/asset needs to be built in many different locations, the utilization of VM becomes very cost effective because cost reduction and ideas that add value to the project can be incorporated into all the buildings to be built later on. The same benefits also apply to unique projects that come with new technology elements and few precedents in that it will allow obtaining of expert opinions.
Blue Eyes Intelligence Engineering \& Sciences Publication

(C) Copyright: All rights reserved. 
It is imperative to get maximum value for the least amount of money when dealing with Projects with very restricted budgets, thus a great need for VM as it seeks to eliminate unnecessary costs. High visibility projects which are kinds of projects sponsored by the government or environmentally sensitive projects require VM to ascertain proper and appropriate implementation because it is important that as little as possible goes wrong to these projects to avoid the media embarrassing the parties involved on the project. VM is not restricted to the types of projects mentioned above, but can be applied to any project/building or asset. VM can be applied to parts of buildings or subdivisions of projects. The general feel is that VM is more beneficial on larger projects due to the fact that there are certain costs associated with a VM study [1]

\section{G. Risks of Value Management}

There are risks in every activity, including the ones that are conceived for the purpose of managing people, activities and/or processes. The principles of management involve different tools, techniques, procedures and methods for the purpose of planning, controlling and regulating people, events, procedure and /or practice. It is expected that there will be some risks in the adopted tools which is part of the risks of the principles of management. With demonstrated benefits of value management, there are some risks that need to be monitored, evaluated, and responded to for the process to be successfully applied in the construction industry. [7] A major risk in the adoption of value management is the level of support from clients, statutory or regulatory bodies as well as from top management staff of an organization. The risk may not be pronounced in countries where the discipline has been embraced and is currently adopted as a project management tool. However, in countries where most of the construction stakeholders still perceive the practice as another cost-cutting exercise geared towards extorting more money from clients, the outcome and recommendations from the team may even be discarded, rendering the whole process a waste of time and resources with no impact on the project at hand. The timing. Another risk that can hinder value management is the choice of the right stage of a project at which to implement it. Some schools of thought believe that it should be carried out at the initial phase before the production of final drawings. The problem with this is that there may not be sufficient information for the team to work with and make reasonable suggestions and recommendations. Another school of thought is of the opinion that the exercise should be introduced after the production of detail drawings. There are two issues with this: one is that the project will have to be delayed for at least a week for the exercise to be conducted. The other issue is that recommendations from the exercise will usually lead to amendments and alterations of the existing design which may be at extra cost to the design team. This may eventually lead to a further delay in the actual commencement of the project.

An uncommon and unpopular opinion is for the practice to be introduced as soon as the commencement of site activities. A major base of argument of this view is that before the commencement of a project, there should have been sufficient information for a value management team to work with and that will enhance the success of the exercise. However, this has many disadvantages as the feedback from the exercise will surely slow down the pace of work, may lead to rework, and an eventual waste of resources regarding part of work that would have been completed before feedback from the value management team. The right timing may depend on projects', clients' and other stakeholders' characteristics. However, regardless of the timing selected for conducting the exercise, the risk must be appropriately evaluated so as not to affect the overall performance of the project.

\section{RESEARCH METHODOLOGY}

The tools that were used to investigate the adequacy of applying Value Management approach included Descriptive Statistics (Frequency Distribution \&Cross Tabulation), multiple linear regression analysis on SPSS 17.0 and MS Excel for data maintenances. The data was gathered exclusively from questionnaire as the research instrument. The questionnaire was designed in line with the objectives of the study. To enhance quality of data obtained, Likert type questions were included whereby respondents indicated the extent to which the variables were practiced in a five point Likert scale.

The study sought to inquire information on various aspects of respondents in three areas: background information in response to the respondents, Level of understanding of value management; drivers and barriers of Value Management.

Target population was professionals from construction companies, construction consultancy firms and government institutions in charge of conception and implementation of large and complex construction companies. These respondents are professionals in charge of managing the projects. i.e., Project Managers, Engineers, Architects and quantity surveyors. The researcher has used the following formula for estimation and sample size determination for finite populations: [9]

\section{$\mathrm{N}=\mathrm{Z}^{2} \mathrm{pq} / \mathrm{e}^{2}$}

Where: $\mathrm{N}=$ required sample size (when the population is more than 10,000). Z2= Standard normal deviation at 95\% confidence level (1.96). $\mathrm{P}=$ Proportion of population having the characteristics. $\mathrm{q}=1-\mathrm{P} . \mathrm{e} 2=$ Degree of precision (at $\pm 10 \%)$

However, taking into consideration of those respondents who might not fill the questionnaire well thus giving erroneous information and those questionnaires that might miss in the process, the sample size was increased by $20 \%$ to cater for this uncertainty. Thus the number of respondents in the questionnaire was found to be 115 in total.

This sample size was distributed amongst key players in construction industry including engineers, architects, quantity surveyors, clients and project managers.

The data was gathered exclusively from questionnaire as the research instrument. The questionnaire was designed in line with the objectives of the study. To enhance quality of data obtained, Likert type questions were included whereby respondents indicated the extent to which the variables were practiced in a five point Likert scale.
Blue Eyes Intelligence Engineering \& Sciences Publication (C) Copyright: All rights reserved. 
The study sought to inquire information on various aspects of respondents in three areas: background information in response to the respondents, Level of understanding of value management; benefits and barriers of Value Management. The test was carried out to determine whether the list of items provided consistently reflect the measure of factors that affect Value Management. The outcome shows that the items are consistent at Cronbach's Alpha of 0.977 and all are relevant for the study.

\section{RESEARCH RESULTS AND FINDINGS}

The responses gathered from the respondents form structured information that is interpreted and discussed in details and in a manner that addresses the research questions presented from the outset of the study. Research findings revealed that VM approach is not used during conception of construction projects in Rwanda mainly due to lack of awareness of this approach. The following elements were assed to arrive at the conclusion and recommendation:

(i) From the information gathered on role and experience of the respondents in construction project management, it is evident that majority of them were the Engineers and Architects since they form part of the majority team that is involved in the conception of the project and this forms the basis of this research. Most of them were experienced between 11-15 years. Despite their experience in construction industry, $80 \%$ of them indicated that they were not aware of VM practice.

(ii) Application of VM during conception of construction projects in Rwanda, according to the findings of this study is at $7 \%$.

(iii) Based on the information gathered from various literature on VM approach, five drivers of value management were listed which respondents were required to respond on and rank them in order of their importance. Reliability test was also done to determine which driver was of more importance while applying $\mathrm{VM}$ in conception of construction project. It was revealed that all factors under consideration are all important to the research study. The correlation coefficients for all items are all above 0.9 therefore we will not consider removing any of these items under study. The study concludes that it is prudent to apply VM approach from the early stage of a project, not simply introduced when the problems occur. It is also concluded in this study that application of Value Management approach to construction projects achieves improved designs, construction and overall value for money.

(iv) Barriers against application of $\mathrm{VM}$ in conception of projects were also discussed. Of all the responses by clients, architects, engineers, quantity surveyors, and project managers, the three top most highly ranked barriers to application of value management in conception of construction projects, were (1) Lack of awareness about VM by construction industry practitioners (2) Lack of training and/or education in VM among industry practitioners and (3) Lack of contractual provisions to support value management.

\section{Application of VM at Conception}

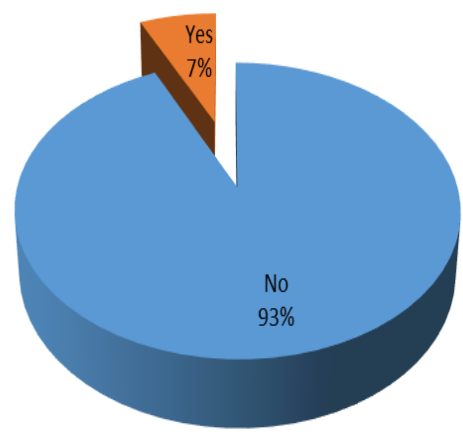

Source: Field Survey, 2019

Figure 1: Application of VM during conception of construction projects in Rwanda

\section{CONCLUSION}

The main objective of this study was to examine the merits of applying value management approach during the conception of construction projects in Rwanda for effective achievement of value for money. The study used a quantitative survey method of research to obtain responses from professional practitioners in construction industry in Rwanda. This tool sought to understand whether VM approach is already in practice in construction industry in Rwanda and what are possible drivers and barriers of VM application in construction projects.

Information gathered from the sampled population indicates that majority of the respondents are not aware of VM approach and only two of them indicated that they were involved in one construction project worth \$20M in Rwanda where VM approach was applied during the conception stage. The study also concludes that, the most hindering blocks to application of VM which need to be addressed were found to be lack of awareness about VM by construction industry practitioners, lack of training and/or education in VM among industry practitioners and lack of contractual provisions to support value management in construction projects contracts.

Recommendation is made on creation of awareness to the stakeholders in construction industry in Rwanda. This can be achieved through education and trainings conducted through such strategic initiatives and platforms like; incorporation of VM as part of curriculum for the fields or domains that are related to conception and implementation of construction projects, training and seminars on VM by relevant institutions and organizations, Continuing Professional Development (CPD). Given the advantages of VM practice in conception of construction projects as witnessed in various literatures on the subject, the researcher recommends that VM practice be adopted in construction industry in Rwanda as a mandatory requirement for conception of all construction projects with a budget of $\$ 20 \mathrm{M}$ and above. This will also among others, incorporate VM practice in the general conditions of contract for their consultancy contracts.
\& Sciences Publication

(C) Copyright: All rights reserved. 


\section{ACKNOWLEDGEMENT}

This is to acknowledge with much gratitude the support and help rendered by JKUAT faculty team during the entire period of pursuing this course.

My special gratitude and sincere appreciations go to Dr. Abednego Gwaya and Dr Githae Wanyona who took the responsibility to guide me in this undertaking. Your invaluable inputs into this work will be forever recognized with a great sense of humility and gratitude.

Last but not least, my thanks to the students of Construction Project Management program that we have sailed together from the start until this far.

However, I will not be honest if I did not mention notable names of those individuals whom we have shared the major part of this academic journey devising and implementing the road map towards completion of this course. Thank you Philbert MBANZA, Jean Claude UWIZEYE, Anaclet NDAHIMAANA and Enock MUSABYIMANA for your support. Your courage, dedication and commitment to this course have always strengthened my resolve to push further during difficult times.

\section{REFERENCES}

1. E. Kwibuka, "Construction, manufacturing sectors main drivers of job creation," The New Times, 2018.

2. O. E. OGUNSANMI, "Value Management Awareness and utilization in Construction Projects in Lagos state, Nigeria," 2014.

3. Miss Apruva J Chavan, "Value Engineering in Construction Industry," 2013.

4. P. Scott M. Smith, "Determining Sample Size".

5. T. Peterson, "Engineer Insists Rukarara Hydropower Plant fine," The New Times, 2011.

6. T. O. Olawumi, E. B. Akinrata and B. T. Arijeloye, "Value Management-creating functional value for construction Project," World Scientific News, Ondo State, 2016.

7. C. Liza, "Value Management in construction Industry. What does it entail and is it a worthwhile practice?" Pretoria, 2009.

8. V. G. Luvara and B. Mwemezi, "Obstacles against Value Management Practice in Building Projects of Dadr es salaam Tanzania," 2017.

9. R. Rwirangira, "Kigali City Council is adding new bypass roads around the Kigali Convention Centre area in Kimihurura as completion of the complex approaches.," The New Times, 2016.

10. M. Gahigi, "Rwanda's construction sector on the rise in 2017," The East African, 2017.

\section{AUTHORS PROFILE}

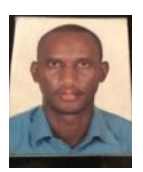

Eng. Rwamuhinda Dick, Bachelor of Civil Engineering, Kigali Institute of Science and Technology (KIST), Master of Construction Project Management, JKUAT.

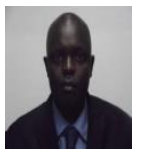

Dr. Abednego Gwaya, B.A (Bldg. Econ.), U.O.N, MSc Civil Eng. Makerere, Ph.D (Const. Eng. \& Mngt).JKUAT. Specialization:

Construction Project Management, Civil Engineering construction, Contract

Documentation, Project Management modeling, Project Procurement Systems and General Quantity Surveying.

Dr. Githae Wanyona, B.A (Bldg. Econ.), U.O.N, M Engineering (Kyoto University, Japan), PhD. (UCT), RSA. Specialization:

Construction Project Management, Construction Contract Documentation, Project Risk MAnagement, Project Procurement Systems and General Quantity Surveying. 